\title{
Editorial
}

\section{HIV/AIDS in its third decade: Renewed critique in social and cultural analysis - An introduction}

Social Theory \& Health (2009) 7, 187-195. doi:10.1057/sth.2009.13

The impetus for this special issue on HIV came from a discussion a few years ago during which we established a shared interest in a revival of the sort of scholarly innovation that characterized the early years of the HIV epidemic. As far back as the early 1980s, social theorists, cultural, critics, artists and others created a vibrant body of work on HIV/AIDS. Working from various theoretical and disciplinary sites they steadfastly emphasized the 'social' for understanding the significance of AIDS and opened up new avenues for critiquing and reimagining scientific, cultural and social responses to infectious disease. At its best, this work served also as an impetus for queer theory, various feminist critiques and a range of research under the rubric of science, medicine and technology studies.

The contributions made by this early work and its effects on public discourse on HIV/AIDS were multiple. Among the more groundbreaking contributions worth underscoring here were analyses that destabilized the neutrality of scientific knowledge and practice, emphasizing the malleability and culturebound nature of its disease definitions (Martin, 1994) as well as activist and other interventions in the organization of its knowledge (Epstein, 1996). Work on the cultural representation of HIV was especially important (Crimp, 1987) and included insightful analyses of how media portrayals contributed to public panic and misunderstanding of HIV infection, constructed 'guilty' versus 'innocent victims' and promoted the stigmatization of gay men, prostitutes, injection drug users, Haitians and others earlier associated with AIDS (Watney, 1987; Patton, 1990). Also of note was research that countered biomedical representations of HIV by foregrounding the experiences of people living with HIV through analyses of illness, identity and sexuality (Adam, 1996); and critiques of expert and programmatic responses to HIV infection, including work on the limits of the models of rational action, that informed public health approaches to HIV prevention (Patton, 1996) and that exposed the contradictory social and political effect of epidemiological reasoning and practice (Oppenheimer, 1992).

As HIV/AIDS nears three decades of response and intervention, theoretically engaged scholarly commentary on the topic is on the wane. We make that 
judgment with care, wary of the dangers of nostalgia and its diminishment of the present against an unequaled, heroic past. We recognize the fine work on HIV and AIDS currently being carried out by anthropologists, cultural critics, sociologists and others addressing, among other questions, the biopolitical dimensions of national and global responses to HIV (for example Biehl, 2007). Notwithstanding these contributions, we have sensed in our teaching, writing and broader work environments a certain disinterest, even closure of thought around HIV/AIDS. It is a development that we see as having a profound impact on the capacity to more effectively deal with an epidemic in which nearly 25 million people have died of AIDS and an estimated 33 million people are now living with HIV (Merson et al, 2008).

We cannot provide a full diagnosis of the fate of theoretical engagement in HIV/AIDS in these brief introductory comments. We can, however, suggest something about the shifts that have occurred of late in the social study of HIV infection. The sources of those shifts are multiple. Here we emphasize one critical development: a set of broad transformations in the organization of social research on health related to the rise of evidence-based medicine.

Evidence-based medicine is an initiative that seeks to govern biomedicine by establishing scientific research as the fundamental ground of medical decisionmaking (Mykhalovskiy and Weir, 2004). It has been a remarkably successful project. Not only has it reshaped biomedical reason and practice, it has exported an ethos and technology of 'evidence-based decision-making' to multiple domains both within and beyond health care. It is without question a complex project with multiple and conflicting effects, not something to be reduced to a singular force that, among its dubious accomplishments, has somehow wrecked critical social research on health. Still, its proliferation in the context of other developments such as the rise of efficiency discourses, the consolidation of health-care managerialism, the growing corporatization of universities and new relations of accountability in the state sector has contributed to shifts in research that discourage theoretically informed critical social inquiry on HIV/ AIDS, among other topics.

At least three developments sourced in evidence-based medicine create troubles for the type of scholarly work promoted by this special issue. First, the injunction to base all manner of health decisions on scientific research introduces a hierarchy of evidence that privileges clinical trials research and, in the realm of 'social' research, epidemiology and positivist social science. Second, it creates a new demand structure for the forms of research that it values. This has involved shifts in funding that promote a narrow vision of applied health research and a consolidation of biomedical and health sciences criteria of research review. Finally, evidence-based medicine has generated new expectations for how research will be used, which restrict appreciation of the value of 
critical, theoretically informed scholarship. The applied project of knowledge 'transfer' or 'translation' discounts relations of knowledge use that aim at questioning or critiquing existing arrangements, instead imagining research as an information product or output that can guide the individual decisions of state policy-makers, health professionals and other 'key stakeholders.'

These developments have helped fuel an apparatus of funding and research committed to creating knowledge for governing health care. This is an organization of research in which health, illness and disease are constituted as governmental problems to be ameliorated by research considered to generate evidence-based solutions and formulated within the established terms of health policy, managerial and professional discourses.

The emergence of a combination antiretroviral therapy (ART) in 1996 enhanced the vulnerability of HIV to this closure of thought and inquiry. The early, critical work on HIV/AIDS was fueled, in large part, by the crisis in scientific and biomedical response to the disease. The appearance of ART helped secure the credibility of the biomedical management of HIV, heightening the status of biomedicine and the health sciences as forms of knowledge guiding pandemic response and tempering at least some of the earlier critiques of the limits of science and biomedicine. ART also gave a boost to the global AIDS industry - that complex of aid agencies, medical relief organizations, international organizations, NGOs, religious groups, philanthropic organizations, research institutes and all manner of consultants concerned with HIV as a health crisis of the 'developing' world - by highlighting new questions about the balance of prevention and treatment in responding to HIV epidemics in low-income countries and by furthering pressures for applied, outcomesbased research. This has been perhaps most visible in the intellectual program of the international AIDS conference series organized by the International AIDS Society. Here, theoretically engaged social and cultural critique is all but absent amid a sea of basic science, clinical research, epidemiology, policy research and a new interest in 'operations research' understood to offer insights on how to efficiently scale-up local HIV/AIDS programs.

Under these conditions, the norms defining how social research on HIV should be conducted, what kinds of questions need posing and what forms of knowledge are most valued increasingly emanate from the applied health sciences. HIV research from the behavioral and health sciences continues to flourish. However, as a recent call to action highlights, much of this work focuses on where to direct discrete interventions, with little attention given to how interventions actually work (Piot et al, 2008, p. 853). In the same discussion, the importance of addressing complexity is noted and emphasis is given to the need to move away from net accounts of behaviors to the more dynamic nature of sexual and social networks. It is, then, even more important that, by contrast, critical social and 
cultural inquiry of HIV has fared far less well. Work drawing on theory to critically reflect on current arrangement appears particularly vulnerable, often viewed as a trifle or excess from within the applied relevancies of evidence-based decisionmaking and the global AIDS industry. In this new research environment, the contributions of early theoretically rich cultural and social research on HIV have been largely eclipsed by the yearning for evidence; the value of deep social science inquiry of HIV is no longer well recognized or well understood.

This special issue of Social Theory and Health intervenes in the contemporary knowledge relations shaping HIV social research. It provides space for social and cultural inquiry of HIV/AIDS that foregrounds theoretical reflection and discourse. We view theoretically reflexive work on HIV from the social sciences and humanities as important contributions in and of themselves, as well as fundamental contributions to contemporary thought and action on HIV/AIDS in its multiple dimensions.

The need to open up scholarly inquiry of HIV/AIDS beyond the parameters set by applied, evidence-based research agendas is all the more pressing given new challenges that have arisen since the early period of innovative cultural and social research. A number of rich trajectories of inquiry are suggested. They include work conceptualizing transformations in the bodily experience of HIV related to the growing pharmaceuticalization of life; theoretical reflection on fundamental shifts in responsibility for HIV transmission promoted by new projects for governing the conduct of people living with HIV, such as 'positive prevention', and new mobilizations of state power can be found in the growing global trend to criminalize HIV transmission/exposure; careful analytic work that would re-animate traditions of critique of HIV-related science by exploring the globalization of clinical scientific research and transformations in the enactment of HIV treatments; research that critically explores the power effects of a burgeoning global apparatus of response to HIV in developing countries; and theoretical work on the nature and implication of shifts in the experience and representation of HIV/AIDS across gender, race and sexual orientation.

The contributions in this special issue offer critical analyses of HIV prevention among gay men in the United States and Australia and of mass treatment and prevention campaigns in Western Africa and South Africa. They were chosen from among 22 papers received in response to a call for submissions, which was distributed widely through professional and disciplinary networks, including medical anthropology and sociology listserves and the Sociologists' AIDS Network. The call invited papers from critical social sciences or cultural studies, written from disciplinary or interdisciplinary perspectives and encompassing theoretical or theoretico-empirical work. All papers were reviewed by at least two external reviewers. The papers published here were written by authors working out of Canada, Australia, the United States and South Africa. 
In 'Government-by-exception: enrolment and experimentality in mass HIV treatment programs in Africa,' Vinh-Kim Nguyen pierces the congratulatory rationality that so often frames the massive deployment of medico-humanitarian assistance for HIV/AIDS in Africa led by international organizations, NGOs and non-African state donors. Nguyen draws on Foucault's late work on the governmentalization of the state and contemporary discussions of Agamben's writings on the state of exception. He asks how to make sense of mass HIV treatment programs in which NGOs, European hospitals and American universities directly govern the lives of populations of people living with HIV in some African countries, holding more control over the delivery of services to them than do their own states, in effect, exercising a power of life or death (p. 196). For Nguyen, the answer takes the form of a hypothesis. Using his fieldwork experience as an anthropologist and physician in Western Africa and devising an analysis that emphasizes continuities between contemporary forms of HIV humanitarianism and the organization of postcolonial biomedical and military power, he proposes that mass HIV treatment campaigns be understood as a novel form of legitimate therapeutic dominance. In doing so, he invites us to consider such programs as forms of biopolitical intervention that invoke a right to intervene in order to save lives on the basis of a representation of HIV as a particular form of emergency. Nguyen's insightful and important analysis emphasizes how mass treatment programs require enrolment: ways of calling a standardized population into being through 'biological and political technologies for constituting populations and transforming bodies and subjectivities' (pp. 213-214).

In contrast to the focus on politics, governance and international aid, the papers by Gary Dowsett, 'Dangerous Desires and Post-Queer HIV Prevention: Rethinking Community, Incitement and Intervention,' and Jorge Fontdevila, 'Framing Dilemmas During Sex: A Micro-Sociological Approach to HIV Risk,' engage with the increasingly nuanced territory of gay sexual cultures.

For Dowsett, the long-term presence of HIV risk demands a review of the matrix of prevention research and interventions. Many gay men have some knowledge and experience of a diverse set of prevention strategies that have developed over the course of the epidemic. Yet their practices may not necessarily accord with what is expected to follow from this knowledge and experience. In order to illustrate this key point while challenging the idea that we necessarily require more research focused on the site, style and motivation for sex, Dowsett uses his own 'situatedness' to expose the inadequacy of studying sexual practices without also recognizing how these embody the cultures we have created through intervention. Declaring that in 2002 he broke his own rule of never having unprotected anal intercourse, he quickly dispenses with the usual reasons offered for taking such a risk. Further, schematizing the 
various theoretical approaches that have informed prevention research to date, he argues that we may have reached the end of the road for simply 'adding' to this repertoire. In place of such a tendency, Dowsett directs us to reflect on the relational and dynamic nature of the social. Sexual cultures are by no means unchanging. The achievements of prevention work are powerful evidence of this point. Dowsett makes an important call to recognize the plurality that now makes up gay sexual cultures and how this continues to evoke new sexual interactions, including those in which condom use or its now marked absence may have multiple meanings. We are invited to reflexively engage with the epidemic in a manner that recognizes that those who live with it, do so in ways affected by our interventions. This involves leaving off the search for coherence premised on a concept of stable subjects and predictable outcomes or, as he puts it, a 'one-size-fits-all' approach to prevention. In its place, it is time to rebuild the research agenda in a manner reflexive to the multiple contingencies out of which are emerging new and more heterogeneous epidemics.

Offering a context-oriented focus that Dowsett's paper suggests is now critical to building safe sex cultures, Jorge Fontdevila illuminates the tricky 'trusting' and self 'protection' thinking that may be informing sexual encounters between Mexican gay and bisexual immigrant men within San Diego gay culture. Fontdevila's paper is a theoretico-empirical response to the over-privileging of individualistic cognitive/rationalist approaches to HIV risk. However, rather than exploring so-called structural determinants of HIV transmission, he draws on interviews in a careful analysis of the micro-dilemmas of HIV 'health cooperation' during sex. Fontdevila's development of an interactional analysis and what he terms 'frame switching' enables us to better understand how mistaken assumptions play out between the immigrant men and US-based men. Importantly, whereas contemporary critiques of the use of identity categories might make us shy away from locating research subjects according to the categories of Latino immigrant and not, here it provides necessary depth to what others have identified as the worrying mismatch of assumptions (Kippax and Race, 2003, p. 8). In contrast to the small sub-set of studies that focus on the changed meanings of sexual cues - notably the suggestion or non-suggestion of condom use - that have emerged with the advent of antiretrovirals and more fractured ideas of infectivity and risk (Flowers, 2001; Adam, 2006; Rosengarten, 2009), Fontdevila provides a cross-cultural dimension to the context in which he is located. The study makes a valuable contribution to the research agenda through its development of the interactionist tradition and, in the course of doing so, provides a rich source of material to assist the effective tailoring of prevention programs.

In the paper 'Sexually-Transmitted Infection and Public Health in South Africa: Educational Campaigns for Prevention, 1935-1948 and 1999-2008,' Alan 
Jeeves and Rosemary Jolly take up the challenge of facilitating more effective HIV prevention in a country where 10 per cent of the population is living with HIV and the number of infections continues to rise. In a subtle but determined manner, they contrast an internationally funded contemporary HIV prevention education campaign called 'LoveLife' with a much earlier campaign against syphilis. The historical examination is illuminating for the way it exposes a series of consistencies in prevention education across the two examples that, it is argued, are responsible for the evident failure of both, notwithstanding significant differences in the tone and product format of the media involved. Reiterating what may be considered one of the underlying themes of this issue, Jeeves and Jolly make us especially aware of the importance of investing in prevention strategies that are tailored to local specificities. Their focus is on the disjuncture that exists between everyday sense-making and biomedical knowledges and, thus, how the uptake of any biomedical intervention knowledge or drugs - relies on research attuned to the difficulties that any of us may experience when reconciling disparate conceptions of risk. In their words, what is necessary is 'a full understanding of the varied social and cultural determinants that affect sexual behaviour in diverse settings' (p. 266). Resonating with the work of others who have highlighted the problematic of the mythical autonomous liberal subject (see for example, Adam, 2006; Holt and Stephenson, 2006; Mykhalovskiy, 2008; Tomso, 2008), Jeeves and Jolly underscore the importance of cultural research attuned to the socio-historico-political processes through which HIV risk emerges, and, therefore, may be averted.

We have compiled the final paper 'Commentaries on the nature of social and cultural research: interviews on HIV/AIDS with Judy Auerbach, Susan Kippax, Steven Epstein, Didier Fassin, Barry Adam and Denis Altman' to offer readers a series of perspectives on the epidemic at this historical juncture. In the paper, a group of prominent scholars and researchers with extensive involvement in HIV research and policy reflect on questions about the role of social theory in their work and about the future possibilities and challenges of theoretically engaged social inquiry on HIV/AIDS. The paper was produced through successive email exchanges, forming a type of individual and collective 'interview by email.'

For those unfamiliar with the array of social, political, ethical and medical changes that have occurred with the advent of HIV antiretroviral treatments in late 1996, it will be evident that there remains an immense amount of work to be carried out by social researchers. The insightful way in which our interviewees reflect on their long-term experience exposes much of what the field has become over the course of time and space: increasing biomedicalization does not necessarily mean that the epidemic itself has subsided or, in many places, become more manageable. Indeed, the difficulties of an epidemic that 
now affects almost every country in the world highlights, perhaps more than any other disease, the extensive role of 'the social' in the complex phenomenon of infection and treatment. On the one hand, the paper provides varying emphases on what it is to do social theory or theoretico-empirical work. On the other hand, it contextualizes these in ways that may resonate for others working in the health field and who find themselves having to account for methodological innovation that extends beyond the conventions of the natural sciences. We are immensely grateful to our interlocutors for the incisive way they have illuminated HIV as in no less urgent need of creative thought and action than that which - pre-antiretrovirals - put this unwanted imaginable on the map as an exemplar of patient activism, medical innovation and radical theoretical development.

We close with a note of thanks. This special issue would not have been possible without the support of the journal editors Paul Higgs and Graham Scambler, the tireless assistance of Miranda Scambler and the contributions of the anonymous reviewers.

\section{About the Authors}

Eric Mykhalovskiy is an associate professor and Canadian Institutes of Health Research New Investigator. His current research focuses on the relationship between HIV prevention and treatment and on the criminalization of HIV transmission/exposure. He is a co-author, with Lorna Weir, of Global Public Health Vigilance: Creating a World on Alert (Routledge).

Marsha Rosengarten is a lecturer and deputy director of the Centre for the Study of Invention and Social Process, at the Sociology Department, Goldsmiths, University of London. She is the author of 'HIV Interventions: Biomedicine and the traffic in information and flesh' (University of Washington Press, 2009).

\section{References}

Adam, B. (1996) Experiencing HIV. New York: Columbia University Press.

Adam, B. (2006) Infectious behaviour: Imputing subjectivity to HIV transmission. Social Theory \& Health 4: 168-179.

Biehl, J. (2007) Will to Live: AIDS Therapies and the Politics of Survival. Princeton and Oxford: Princeton University Press.

Crimp, D. (ed.) (1987) AIDS: Cultural analysis, cultural activism. October 43, special issue.

Dowsett, G. (2009) Dangerous desires and post-queer HIV prevention: Rethinking community, incitement and intervention. Social Theory \& Health 7(3): 218-240. 
Epstein, S. (1996) Impure Science: AIDS, Activism, and the Politics of Knowledge. Berkeley, CA: University of California Press.

Flowers, P. (2001) Gay men and HIV/AIDS risk management. Health: An Interdisciplinary Journal for the Social Study of Health, Illness and Medicine 5: 50-75.

Fontdevila, J. (2009) Framing dilemmas during sex: A micro-sociological approach to HIV risk. Social Theory \& Health 7(3): 241-263.

Holt, M. and Stephenson, N. (2006) Living with HIV and negotiating psychological discourse. Health: An Interdisciplinary Journal for the Social Study of Health, Illness and Medicine 10: 211-231.

Jeeves, A. and Jolly, R. (2009) Sexually-transmitted infection and public health in South Africa: Educational campaigns for prevention 1935-48 and 1999-2008. Social Theory \& Health 7(3): 264-282.

Kippax, S. and Race, K. (2003) Sustaining safe practice: Twenty years on. Social Science \& Medicine 57: $1-12$.

Martin, E. (1994) Flexible Bodies: Tracking Immunity in American Culture from the Days of Polio to the Age of AIDS. Boston, MA: Beacon Press.

Merson, M.H., O’Malley, J., Serwadda, D. and Apisuk, C. (2008) HIV prevention 1: The history and challenge of HIV prevention. Lancet 372: 475-488.

Mykhalovskiy, E. (2008) Beyond decision making: Class, community organizations and the healthwork of people living with HIV/AIDS. Contributions from institutional ethnographic research. Medical Anthropology: Cross Cultural Studies in Health and Illness 27: 136-163.

Mykhalovskiy, E. and Weir, L. (2004) The problem of evidence-based medicine: Directions for social science. Social Science \& Medicine 59: 1059-1069.

Nguyen, V.K. (2009) Government-by-exception: Enrolment and experimentality in mass HIV treatment programs in Africa 7(3): 196-217.

Oppenheimer, G.M. (1992) Causes, cases, and cohorts: The role of epidemiology in the historical construction of AIDS. In: E. Fox and D.M. Fee (eds.) AIDS. The Making of a Chronic Disease. Berkeley, CA: University of California Press.

Patton, C. (1990) Inventing AIDS. New York: Routledge.

Patton, C. (1996) Fatal Advice: How Safe-Sex Education Went Wrong. Durham, NC: Duke University Press.

Piot, P., Bartos, M., Larson, H., Zewdie, D. and Mane, P. (2008) HIV prevention 6: Coming to terms with complexity: A call to action for HIV prevention. Lancet 372: 845-859.

Rosengarten, M. (2009) HIV interventions: Biomedicine and the traffic between information and flesh. For The Book Series: In Vivo: Cultural Mediations Of Biomedical Science, In: P. Thurtle and R. Mitchell (eds.) Seattle, WA: University Of Washington Press.

Tomso, G. (2008) Viral sex and the politics of life. South Atlantic Quarterly 107: 265-285.

Watney, S. (1987) Policing Desire: Pornography, AIDS and the Media. London: Metheun.

Eric Mykhalovskiy Department of Sociology, York University, Vari Hall, 4700 Keele Street, Toronto, Ontario, Canada, M3J 1P3

E-mail: ericm@yorku.ca

Marsha Rosengarten Department of Sociology, Goldsmiths, University of London, New Cross, London, SE14 6NW E-mail: m.rosengarten@gold.ac.uk 